\section{Meta-analysis programs}

\section{RALF SCHWARZER \\ Freie Universität Berlin, Berlin, West Germany}

The term meta-analysis (Glass, 1976) refers to a set of data analysis strategies for the integration and comparison of empirical research findings in the absence of the original data. A variety of advanced techniques for conducting meta-analyses are described in textbooks published recently (e.g., Hedges \& Olkin, 1985; Rosenthal, 1984; Wolf, 1986). The present program package has been designed to provide a convenient tool for handling different kinds of data sets and different algorithms. It can be considered as a more advanced alternative to the programs offered by Gorman, Primavera, and Karras (1983).

After typing in "META," a main menu appears with the following 10 subprogram options:

1. Data File Management. The filer allows input of data according to three file structures, which are intended for use with either probabilities $p$, effect sizes $d$, or effect sizes $r$ (correlations). The filer allows the user to list, print, append, edit, and select data records.

2. Combination of Effect Sizes $d$. This subroutine runs a meta-analysis for $d$ values obtained from experimental studies. $d$ is defined as the standardized difference between means, that is, the mean of the experimental group minus the mean of the control group or the pooled standard deviation (Fricke \& Treinies, 1985; Glass, McGaw, \& Smith, 1981; Hedges \& Olkin, 1985).

3. Cluster Analysis of Effect Sizes $d$. The distribution of effect sizes from a number of studies may be heterogeneous. Grouping smaller numbers of studies into more homogeneous subsets is achieved by a disjoint cluster analysis. By employing this strategy and by inspecting the resultant subgroups, potential moderator variables can be detected.

4. Combinations of Effect Sizes $r$ (Correlations). This program runs a meta-analysis for effect sizes $r$ obtained either directly from correlational studies or from statistics that have been transformed with program 7 .

5. Cluster Analysis of Effect Sizes $r$ (Correlations). Same as in program 3 for effect sizes $d$.

6. Combination of Probabilities $p$. This program uses the Stouffer method of integrating one-tailed exact $p$ values after transformation to the normal distribution $Z$. It should be used only when effect sizes are unavailable.

7. Transformation of Coefficients. Not all studies in the literature provide the appropriate effect sizes. Instead, some report $t$ values, $F$ values, chi-squares, or other statistics. In such cases, a transformation is required and can easily be done by this program.

8. Weighted Means. Some authors of empirical studies report not only one but a number of effect sizes based on several independent subsamples. In this case, the meta-analyst has to decide whether all effect sizes should be considered separately or should be pooled. It is for the latter purpose that this program has been written.

9. Significance of Correlations. This program determines whether a correlation is statistically significant and whether coefficients differ significantly from each other.

10. Stem-and-Leaf Display for Correlations. This is a convenient display technique for effect sizes $r$, and it provides more information than traditional histograms.

Input. After typing in "META," the program package is completely menu driven. The filer allows input for three kinds of data: $p$ values, $d$ values, and $r$ values. Sample size input is necessary. Reliabilities are optional, and missing values are considered.

Output. Brief results are presented on the screen, and line printer output is optional.

Hardware and Language. The program package has been written in Turbo Pascal for the IBM PS/2, IBM PC, or compatibles (MS-DOS 2.10 with 256K RAM). It requires $212 \mathrm{~K}$ of disk storage space.

Manual. A 16-page manual including formulas and examples is provided on the disk as a text file called "META.DOC."

Availability. Version 3 of this program package is available either on a 5.25-in. or on a 3.5-in. floppy disk. The software is free of charge, but a fee of $\$ 10$ is requested for update information, foreign air mail postage, and handling. The software can be ordered by sending to the author a formatted disk accompanied by a check. The user may feel free to make copies for others, but not for commercial use.

\section{REFERENCES}

Fricke, R., \& Treinies, G. (1985). Einführung in die Metaanalyse. Bern: Huber.

GLAss, G. V. (1976). Primary, secondary and meta-analysis of research. Educational Researcher, 10, 3-8.

Glass, G. V., McGAW, B., SMITH, M. L. (1981). Meta-analysis in social research. Beverly Hills: Sage.

Gorman, B. S., Primavera, L. H., Karras, A. (1983). A microcomputer program package for metaanalysis. Behavior Research Methods \& Instrumentation, 15, 617

HEDGES, L. V., \& OLKIN, I. (1985). Statistical methods for meta-analysis. New York: Academic Press.

Rosenthal, R. (1984). Meta-analytic procedures for social research. Beverly Hills: Sage.

WoLf, F. M. (1986). Meta-analysis: Quantitative methods for research synthesis. Beverly Hills: Sage.

(Revision accepted for publication February 2, 1988.)
The author's mailing address is Freie Universität Berlin, Institut für Psychologie, FB 12 WE 7, Habelschwerdter Allee 45, D-1000 Berlin 33, West Germany. 